\title{
Serum Glucose Measurement after Five to Six Hours is Comparable to Eight Hours Fasting in Ramadan
}

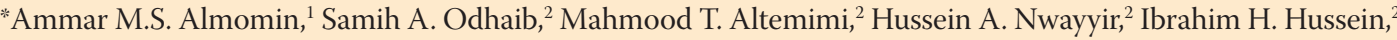
Haider A.Y. Alidrisi, ${ }^{2}$ Nassar T.Y. Alibrahim, ${ }^{2}$ Abbas A. Mansour ${ }^{2}$

\begin{abstract}
Objectives: This study aimed to evaluate whether a shorter fasting duration of five to six hours can be used as an alternative to the usually recommended eight hours for fasting glucose measurement. Methods: This one-month observational, cross-sectional study was conducted during Ramadan (May to June) 2019. It included those attending Faiha Specialized Diabetes, Endocrine and Metabolism Center, Basrah, Iraq; all individuals ate a pre-dawn meal (suhoor) followed by a complete fast for many hours. Two fasting serum glucose (FSG) venous samples were taken; the first was taken five to six hours and the second eight hours after the pre-dawn meal. Participants were divided into two groups: individuals with type 2 diabetes mellitus (T2DM) and those with a normal glucose level. T2DM patients were further subdivided into three groups: those without treatment, those on oral antidiabetic drugs (OAD) and those using insulin and OAD. Results: A total of 200 individuals participated in this study. There was no significant difference found between the mean FSG levels in the first and second samples for those without T2DM $(104.5 \pm 21.4 \mathrm{mg} / \mathrm{dL}$ versus $104.8 \pm 12.6 \mathrm{mg} / \mathrm{dL} ; P=0.80)$ as well as those with T2DM $(235.0 \pm 107.0 \mathrm{mg} / \mathrm{dL}$ versus $230.0 \pm 105.0 \mathrm{mg} / \mathrm{dL} ; P=0.20)$. Untreated T2DM patients had non-significant FSG readings for the two samples $(194.0 \pm 151.5 \mathrm{mg} / \mathrm{dL}$ versus $193.9 \pm 128.9 \mathrm{mg} / \mathrm{dL} ; P=0.90)$. Patients on insulin and OAD showed a similar pattern of FSG $(268.0 \pm 111.0 \mathrm{mg} / \mathrm{dL}$ versus $269.0 \pm 114.0 \mathrm{mg} / \mathrm{dL})$. However, the two FSG samples were found to be significantly different among patients on OAD $(220.0 \pm 78.0 \mathrm{mg} / \mathrm{dL}$ versus $207.0 \pm 77.0$ $\mathrm{mg} / \mathrm{dL} ; P=0.01)$. Conclusion: The fasting duration of five to six hours can give a comparable measurement of FSG as that obtained after eight hours.
\end{abstract}

Keywords: Glucose; Fasting; Duration of Therapy; Diabetes Mellitus; Iraq.

\section{AdVANCES IN KNOWLEDGE}

Fasting five to six hours showed comparable serum glucose measurements to fasting eight hours.

\section{Application to Patient Care}

Shortening the duration of fasting will reduce the waiting time to obtain a valid sample after the last meal.

Most benefits would be for those who have a limited time for medical services.

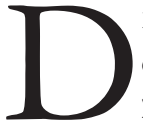
ISRUPTION IN THE TYPICAL CYCLICAL PATTERN of glucose tolerance is the hallmark of type 2 diabetes mellitus (T2DM). Thus, understanding the normal control of glucose metabolism hour-by-hour is critical to achieve optimal diabetes care. The current recommendations emphasise the standardised measurement of fasting plasma glucose (FPG) after overnight fasting for at least eight hours to assess the magnitude of basal glucose abnormalities. ${ }^{1-5}$ However, the discordance with other diagnostic tests and uncertainty regarding the duration of fasting reported by some individuals raises a doubt about the applicability of the current diagnostic criteria for diagnosing diabetes mellitus (DM). ${ }^{6,7}$

Although plasma is devoid of red and white blood cells, they still contain platelets, which consume glucose over time. On the other hand, the serum is free from any cells and hence, would be suitable for determining blood glucose level, especially when there is a time delay in the measurement. If assayed immediately, blood glucose measured in fluoride plasma correlated linearly with blood glucose in the serum; the serum value is lower than the corresponding fluoride plasma value by $1.15 \%{ }^{8}$ As this may not be physiologically relevant, serum may be used as an alternative for blood glucose determination with an error rate of $1.15 \%{ }^{8}$

Despite wide variations in glucose flux in feeding and fasting states, blood glucose is maintained in a narrow range; late-night meals can interrupt healthy sleep and usually affects glucose control in patients with DM. However, the circadian rhythm of cortisol is robust and minimally affected. ${ }^{4,9,10}$

This study aimed to evaluate whether a shorter fasting duration of five to six hours can substitute the standard glucose measurement after eight hours. 


\section{Methods}

A one-month observational, cross-sectional study was conducted during the month of Ramadan (May to June) in 2019. This study included individuals with different demographic characteristics attending Faiha Specialized Diabetes, Endocrine and Metabolism Center (FDEMC) in Basrah, Iraq. All individuals shared the standard behaviour of eating a pre-dawn meal, also known as suhoor, at approximately 3 AM followed by a complete fast (null by mouth) for many hours. Two fasting serum glucose (FSG) samples were collected from each participant, the first sample was taken five to six hours and the second eight hours after the pre-dawn meal.

The exclusion criteria were as follows: non-fasting or incomplete fasting state; patients with type $1 \mathrm{DM}$; fasting without a prior pre-dawn meal; individuals who did not have a real pre-dawn meal (i.e. continued to eat frequent small meals until fasting time); and night-shift workers.

The participants were divided into two groups: individuals with T2DM and individuals without T2DM. Individuals with T2DM were subdivided according to the modality of treatment into patients on only oral antidiabetic (OAD) medications, patients on insulin and OAD and patients with no treatment. Demographic characteristics, such as gender, age and body mass index (BMI), the timing of meals, fasting pattern and the type of treatment for T2DM patients were collected.

After ensuring a fasting state for five to six hours, a venous blood sample of $2-3 \mathrm{~mL}$ was collected in a plain test tube. The samples were immediately transferred to the laboratory and were allowed to be clotted then centrifuged prior to the estimation of FSG by (COBAS, INTEGRA 400 PLUS, Roche Company, Switzerland). This procedure was repeated after eight hours of fasting for each individual.

Data were entered and matched using Microsoft Excel (Microsoft Corp., Redmond, Washington, USA); subsequently, the different variables were analysed using Statistical Package for the Social Sciences (SPSS), Version 23.0 (IBM Corp., Chicago, Illinois, USA). The study used mean \pm standard deviation or frequency for data expression. A paired t-test was used to compare the difference between the mean FSG readings in the two samples. A $P$ value of $<0.05$ was considered statistically significant.

The study was designed to show the efficacy of fasting for only five to six hours to attain a valid fasting glucose measurement compared to the standard eight-hour fasting. If the mean difference between the two samples was less than $6 \mathrm{mg} / \mathrm{dL}$, they would be considered equivalent on the assumption that variation within this limited range would unlikely affect medical decisions in clinical practice.

All participants were given a detailed explanation of the study and written consent was obtained from each participant before the day of the examination. The FDEMC ethical committee approved the study.

\section{Results}

A total of 200 individuals were included in this study. Participants had a mean age of $45.6 \pm 14.4$ years and the majority were male ( $\mathrm{n}=113,56.5 \%)$. There were 115 participants (57.5\%) had T2DM, which were further subdivided according to the type of treatment into individuals on $\operatorname{OAD}(\mathrm{n}=54,47.0 \%)$, individuals on insulin and $\mathrm{OAD}(\mathrm{n}=45,39.1 \%)$ and individuals not on any medication for T2DM $(\mathrm{n}=16,13.9 \%)$ [Table 1].

The mean FSG after five to six hours for nonT2DM individuals was $104.5 \pm 21.4 \mathrm{mg} / \mathrm{dL}(5.79 \pm 1.18$ $\mathrm{mmol} / \mathrm{L})$ compared to the eight-hour sample which was $104.8 \pm 12.6 \mathrm{mg} / \mathrm{dL}(5.82 \pm 0.70 \mathrm{mmol} / \mathrm{L})$; the mean difference was insignificant at $-0.2 \pm 15.9 \mathrm{mg} /$ $\mathrm{dL}(0.01 \pm 0.88 \mathrm{mmol} / \mathrm{L} ; P=0.80)$. While for T2DM patients, the mean FSG was $235.0 \pm 107.0 \mathrm{mg} / \mathrm{dL}$ $(13.04 \pm 5.94 \mathrm{mmol} / \mathrm{L})$ after five to six hours and 230.0 $\pm 105.0 \mathrm{mg} / \mathrm{dL}(12.77 \pm 5.83 \mathrm{mmol} / \mathrm{L})$ after eight hours of fasting, with a mean insignificant difference of $5.6 \pm$ $45.6 \mathrm{mg} / \mathrm{dL}(0.31 \pm 2.53 \mathrm{mmol} / \mathrm{L} ; P=0.20)$. According to the type of therapy for T2DM, the mean FSG values for untreated patients were $194.0 \pm 151.5 \mathrm{mg} / \mathrm{dL}$ (10.77 $\pm 8.41 \mathrm{mmol} / \mathrm{L}$ ) after five to six hours of fasting and

Table 1: Characteristics of the study's participants $(\mathrm{N}=200)$

$\begin{array}{lc}\text { Characteristic } & \mathbf{n}(\%) \\ \text { Mean age in years } & 45.6 \pm 14.4 \\ \text { Mean BMI } \pm \text { SD } & 31.3 \pm 6.4 \\ \text { Gender } & 113(56.5) \\ \text { Male } & 87(43.5) \\ \text { Female } & \\ \text { Diabetic condition } & 85(42.5) \\ \text { Non-T2DM } & 115(57.5) \\ \text { T2DM } & 16(13.9) \\ \text { Type of therapy for T2DM patients }(\mathbf{n}=115) & 54(47.0) \\ \text { No therapy } & 45(39.1) \\ \text { OAD } & \\ \text { Insulin with OAD } & \\ \begin{array}{l}\text { SD = standard deviation; BMI = body mass index; T2DM = type } 2 \\ \text { diabetes mellitus; OAD = oral antidiabetic medications. }\end{array}\end{array}$


Table 2: Comparison of fasting serum glucose measurements between five to six hours and eight hours of fasting

\begin{tabular}{|c|c|c|c|c|c|c|}
\hline \multirow[t]{2}{*}{ Parameters } & \multicolumn{3}{|c|}{ Mean fasting serum glucose in $\mathrm{mg} / \mathrm{dL} \pm \mathrm{SD}$} & \multirow{2}{*}{$\begin{array}{l}95 \% \mathrm{CI} \text { for the } \\
\text { mean difference }\end{array}$} & \multirow[t]{2}{*}{$\mathbf{t}$} & \multirow[t]{2}{*}{$P$ value } \\
\hline & $5-6$ hours & 8 hours & Difference & & & \\
\hline \multicolumn{7}{|l|}{ Diabetic condition } \\
\hline Non-T2DM & $104.5 \pm 21.4$ & $104.8 \pm 12.6$ & $-0.2 \pm 15.9$ & $-0.37-3.1$ & -0.1 & 0.80 \\
\hline T2DM & $235.0 \pm 107.0$ & $230.0 \pm 105.0$ & $5.6 \pm 45.6$ & $-2.8-14.0$ & 1.3 & 0.20 \\
\hline \multicolumn{7}{|c|}{ Type of therapy for T2DM patients } \\
\hline No therapy & $194.0 \pm 151.5$ & $193.9 \pm 128.9$ & $0.06 \pm 40.1$ & $-21.3-0.9$ & 0.006 & 0.90 \\
\hline OAD & $220.0 \pm 78.0$ & $207.0 \pm 77.0$ & $13.1 \pm 37.8$ & $2.8-23.4$ & 2.5 & 0.01 \\
\hline Insulin with $\mathrm{OAD}$ & $268.0 \pm 111.0$ & $269.0 \pm 114.0$ & $-1.4 \pm 54.7$ & $-17.8-15.0$ & -0.1 & 0.80 \\
\hline
\end{tabular}

$S D=$ standard deviation; $C I=$ confidence interval; $T 2 D M=$ type 2 diabetes mellitus; $O A D=$ oral antidiabetic medications.

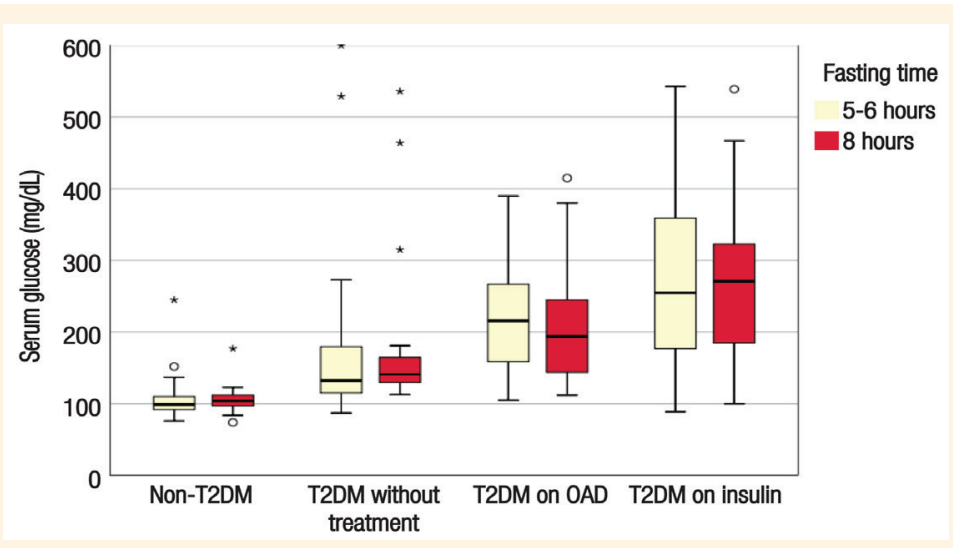

Figure 1: Boxplots of serum glucose measurements after five to six hours and eight hours fasting among the study's participants.

$O A D=$ oral antidiabetic medications; $T 2 D M=$ type 2 diabetes mellitus.

$193.9 \pm 128.9 \mathrm{mg} / \mathrm{dL}(10.76 \pm 7.15 \mathrm{mmol} / \mathrm{L})$ after eight hours $(P=0.90)$. Among T2DM patients on OAD, the FSG mean values were $220.0 \pm 78.0 \mathrm{mg} / \mathrm{dL}(12.21 \pm$ $4.33 \mathrm{mmol} / \mathrm{L})$ after five to six hours and $207.0 \pm 77.0$ $\mathrm{mg} / \mathrm{dL}(11.49 \pm 4.27 \mathrm{mmol} / \mathrm{L})$ after eight hours of fasting with a mean significant difference of $13.1 \pm 37.8$ $\mathrm{mg} / \mathrm{dL}(0.73 \pm 2.10 \mathrm{mmol} / \mathrm{L} ; P=0.01)$. For patients on insulin with OAD, the FSG mean values were $268.0 \pm$ $111.0 \mathrm{mg} / \mathrm{dL}(14.87 \pm 6.16 \mathrm{mmol} / \mathrm{L})$ and $269.0 \pm 114.0$ $\mathrm{mg} / \mathrm{dL}(14.93 \pm 6.33 \mathrm{mmol} / \mathrm{L})$ at five to six hours and after eight hours of fasting, respectively, with a mean insignificant difference of $-1.4 \pm 54.7 \mathrm{mg} / \mathrm{dL}(0.08 \pm$ $3.04 \mathrm{mmol} / \mathrm{L} ; P=0.80$ ) [Table 2 and Figure 1 ].

\section{Discussion}

Overnight FPG measurement is a core component of glycaemic regulation in T2DM and related disorders. However, there is no singular definition of a fasting state; the World Health Organization recommends an 8-14 hours of fasting while the American Diabetes Association defines fasting as no caloric consumption for at least eight hours. ${ }^{2,3}$ In the current study, the mean FSG value after five or six hours was similar to the value obtained after eight hours as the difference being less than $6 \mathrm{mg} / \mathrm{dL}$ which seems practically irrelevant.

Moebus et al. measured the hourly decrease in FPG since the last nightly meal in healthy individuals. They found a non-significant decrease (0.16-0.43 mg/ dL) for each additional fasting hour. ${ }^{4}$ Unexpectedly, they found that three hours of fasting is sufficient to give a comparable FPG reading similar to that obtained after eight hours. ${ }^{4}$ These results were ascertained by the British Regional Heart Study. ${ }^{11}$

Glucose homeostasis is never constant. ${ }^{12}$ The human body can maintain normal blood glucose levels by modifying insulin response to stimulate glucose disposal under the tightly-controlled circadian pattern. ${ }^{13,14}$ However, the relative contribution of the circadian versus the behavioural cycle is unclear. ${ }^{15}$ Generally, the endogenous hormonal control of glucose homeostasis precedes the influential role of the suprachiasmatic nucleus (SCN), which occurs later throughout the day. ${ }^{16}$ 
The FPG and plasma insulin maintain a nadir overnight in healthy individuals, with a modest, transient elevation in insulin secretion rate (ISR) at pre-dawn to restrain endogenous glucose production (EGP) and prevent hyperglycaemia. ${ }^{17,18}$ The increased insulin requirement at dawn had been attributed to either increased insulin clearance that may increase almost 2 -fold or decreased insulin action and hepatic insulin resistance. ${ }^{19}$

Morris et al. showed insignificant changes in FPG, insulin, ISR and growth hormone (GH) after five and eight hours of overnight fasting. ${ }^{15}$ Healthy humans have a time-of-day variation in glucose tolerance with highest in the early hours of the day and a trough at night; ${ }^{20}$ however, patients with diabetes show marked fluctuations. ${ }^{4,13}$

In the current study, which was conducted during the early daytime hours, individuals without diabetes had FSG readings in the normal upper range after eight hours of fasting. The FSG readings did not show a significant difference between the 5-6 hour and 8-hour samples, which matches the cycle of internal glucose metabolism. ${ }^{20}$ On the other hand, patients with T2DM had fasting hyperglycaemia according to diagnostic guidelines. ${ }^{2,3}$

The 'dawn phenomenon' could explain the early morning hyperglycaemia in T2DM patients. This event had been observed in patients with diabetes, and even in some individuals without diabetes, where glucose concentration peaks before the onset of daily activity. ${ }^{7,16,19}$ When plasma glucose is high before the start of an activity, humans seem to be more glucose-tolerant, with a preserved glucose homeostasis during the day. ${ }^{16}$ Nocturnal elevations in GH and early morning increases in cortisol secretion may contribute to this phenomenon by stimulating EGP through gluconeogenesis and glycogenolysis. ${ }^{21-24}$

Van Cauter et al. evaluated individuals for glucose and insulin responses after they consumed two low caloric mixed meals in the morning and evening. They found no difference in FPG levels between five and eight hours, while cortisol level peaked after five hours and increased slightly more than that after eight hours; however, the difference is insignificant. Van Cauter et al. suggest the possible contribution of cortisol in carbohydrate tolerance, given the failure of insulin secretion to increase in proportion to changes in post-meal glucose responses. ${ }^{25}$ The changes in cortisol concentration occurred following changes in EGP for the control group, while for patients with diabetes, EGP increased three hours before a rise in cortisol. Moreover, the later decline in cortisol does not accompany the fall in EGP and this might be due to defective SCN activity in patients with diabetes and/or nonlinear personal behaviour. ${ }^{23,25}$

Many studies found that individuals without diabetes have a steady state in terms of glucose utilisation, insulin concentration, EGP and glucagon, while those with diabetes exhibit a slight increase in glucose utilisation after fasting for eight hours compared to five hours which reflects the rise in the EGP during that time. . $^{19,23,26}$

A Danish study explained the non-linear inverse relationship between insulin sensitivity and glucagon response and described high fasting glucagon level versus lower insulin sensitivity and inadequate glucagon suppression after meals. ${ }^{27}$

Monnier et al. found that OAD does not adequately control the prebreakfast hyperglycaemia that occurs between 6 AM and 8 AM particularly in the presence of dawn phenomenon, even when they are given in combination. Sulphonylureas increases the risk of developing afternoon or evening hypoglycaemia after dose adjustment to counteract the early morning hyperglycemia. ${ }^{28,29}$ Oral incretin-based therapies may improve blood glucose in the postprandial but not during the fasting period. ${ }^{30}$ On the contrary, the evening administration of basal insulin is effective in abolishing the 'dawn phenomenon' by restraining EGP and lipolysis. ${ }^{17}$

The present study shows no significant difference in the first and second FSG readings in patients with diabetes, as well as in individuals without diabetes. The only exception was for those with T2DM using only $\mathrm{OAD}$, who showed a significant difference between the two fasting readings.

There are several limitations to this study. First, this study could not determine whether the FSG changes after fasting for five to six and eight hours reflected the effect of the duration of prior fasting or real circadian modulation. Second, the quality and patterns of night sleep that impact FSG levels were not assessed. Third, this study did not determine the precise timing and amount of last caloric intake, as this was self-reported and, therefore, subject to error and potential bias. Although, approximate recordings of the timing of food intake were collected, it was not possible to identify which ingestions were considered by the participants as meals. Fourth, the exercise effect was not estimated. Lastly, the responses of the counter-regulatory hormones and melatonin during and after six and eight hours of fasting were not measured; this may be a potential topic to be explored in future research. 


\section{Conclusion}

There was no significant difference in FSG after five to six and eight hours fasting in individuals with or without T2DM. The minimal fasting duration to assess FSG can be shortened to five to six hours and there is no need to fast an extra two to three hours. This study's findings support the recommendation of standardisation of fasting duration as it is essential in clinical studies that deal with glycaemic control. Further studies are needed to evaluate the appropriate timing and duration of fasting in non-Ramadan fasters, as well as the evaluation of the effect of sleep quality and the circadian rhythm on the glycaemic pattern.

\section{CONFLICT OF INTEREST}

The authors declare no conflicts of interest.

\section{FUNDING}

No funding was received for this study.

\section{AUTHORS' CONTRIBUTION}

AMSA designed the study. MTA, HAN and IHH planned and supervised the work. AAM was the project director. All authors collected the data. HAYA and NTYA performed the computational framework and analysed the data. SAO drafted the manuscript. All authors reviewed and edited the manuscript. All authors approved the final version of the manuscript.

\section{References}

1. Sitasuwan T, Lertwattanarak R. Prediction of type 2 diabetes mellitus using fasting plasma glucose and HbA1c levels among individuals with impaired fasting plasma glucose: A crosssectional study in Thailand. BMJ Open 2020; 10:e041269. https://doi.org/10.1136/bmjopen-2020-041269.

2. American Diabetes Association. 2. Classification and diagnosis of diabetes: Standards of medical care in diabetes-2021. Diabetes Care 2021; 44:S15-33. https://doi.org/10.2337/dc21-S002.

3. World Health Organization. Classification of diabetes mellitus. From: https://apps.who.int/iris/handle/10665/325182 Accessed: Jan 21.

4. Moebus S, Göres L, Lösch C, Jöckel KH. Impact of time since last caloric intake on blood glucose levels. Eur J Epidemiol 2011; 26:719-28. https://doi.org/10.1007/s10654-011-9608-z.

5. Li Y, Teng D, Shi X, Qin G, Qin Y, Quan H, et al. Prevalence of diabetes recorded in mainland China using 2018 diagnostic criteria from the American Diabetes Association: National cross sectional study. BMJ 2020; 369:m997. https://doi.org/10.1136/ bmj.m997.

6. Tucker LA. Limited agreement between classifications of diabetes and prediabetes resulting from the OGTT, hemoglobin A1c, and fasting glucose tests in 7412 U.S. adults. J Clin Med 2020; 9:2207. https://doi.org/10.3390/jcm9072207.

7. Bolli GB, Gerich JE. The "dawn phenomenon"--a common occurrence in both non-insulin-dependent and insulin-dependent diabetes mellitus. N Engl J Med 1984; 310:746-50. https:// doi.org/10.1056/NEJM198403223101203.
8. Frank EA, Shubha MC, D'Souza CJ. Blood glucose determination: plasma or serum? J Clin Lab Anal 2012; 26:317-20. https:// doi.org/10.1002/jcla.21524.

9. Steiger A. Sleep and the hypothalamo-pituitary-adrenocortical system. Sleep Med Rev 2002; 6:125-38. https://doi.org/10.1053/ smrv.2001.0159.

10. Jerjes WK, Cleare AJ, Peters TJ, Taylor NF. Circadian rhythm of urinary steroid metabolites. Ann Clin Biochem 2006; 43:287-94. https://doi.org/10.1258/000456306777695564.

11. Emberson JR, Whincup PH, Walker M, Thomas M, Alberti KG. Biochemical measures in a population-based study: Effect of fasting duration and time of day. Ann Clin Biochem 2002; 39:493-501. https://doi.org/10.1258/000456302320314511.

12. Radziuk J, Pye S. Production and metabolic clearance of glucose under basal conditions in Type II (non-insulin-dependent) diabetes mellitus. Diabetologia 2001; 44:983-91. https://doi.org/1 $0.1007 / \mathrm{s} 001250100589$.

13. Stumvoll M, Tataranni PA, Stefan N, Vozarova B, Bogardus C. Glucose allostasis. Diabetes 2003; 52:903-9. https://doi.org/10.2 337/diabetes.52.4.903.

14. Base SA, Fang MZ, Rustgi V, Zarbl H, Androulakis IP. At the interface of lifestyle, behavior, and circadian rhythms: Metabolic implications. Front Nutr 2019; 6:132. https://doi.org/10.3389/ fnut.2019.00132

15. Morris CJ, Yang JN, Garcia JI, Myers S, Bozzi I, Wang W, et al. Endogenous circadian system and circadian misalignment impact glucose tolerance via separate mechanisms in humans. Proc Natl Acad Sci U S A 2015; 112:E2225-34. https://doi.org/10.1073/ pnas. 1418955112.

16. la Fleur SE, Kalsbeek A, Wortel J, Fekkes ML, Buijs RM. A daily rhythm in glucose tolerance: a role for the suprachiasmatic nucleus. Diabetes 2001; 50:1237-43. https://doi.org/10.2337/ diabetes.50.6.1237.

17. Sharma A, Varghese RT, Shah M, Man CD, Cobelli C, Rizza RA, et al. Impaired insulin action is associated with increased glucagon concentrations in nondiabetic humans. J Clin Endocrinol Metab 2018; 103:314-19. https://doi.org/10.1210/jc.2017-01197.

18. Porcellati F, Lucidi P, Bolli GB, Fanelli CG. Thirty years of research on the dawn phenomenon: Lessons to optimize blood glucose control in diabetes. Diabetes Care 2013; 36:3860-2. https://doi.org/10.2337/dc13-2088.

19. Arslanian S, Ohki Y, Becker DJ, Drash AL. Demonstration of a dawn phenomenon in normal adolescents. Horm Res 1990; 34:27-32. https://doi.org/10.1159/000181791.

20. Saad A, Dalla Man C, Nandy DK, Levine JA, Bharucha AE, Rizza RA, et al. Diurnal pattern to insulin secretion and insulin action in healthy individuals. Diabetes 2012; 61:2691-700. https://doi.org/10.2337/db11-1478.

21. Campbell PJ, Bolli GB, Cryer PE, Gerich JE. Pathogenesis of the dawn phenomenon in patients with insulin-dependent diabetes mellitus. Accelerated glucose production and impaired glucose utilization due to nocturnal surges in growth hormone secretion. N Engl J Med 1985; 312:1473-9. https://doi.org/10.10 56/NEJM198506063122302.

22. Trümper BG, Reschke K, Molling J. Circadian variation of insulin requirement in insulin dependent diabetes mellitus the relationship between circadian change in insulin demand and diurnal patterns of growth hormone, cortisol and glucagon during euglycemia. Horm Metab Res 1995; 27:141-7. https:// doi.org/10.1055/s-2007-979926.

23. Radziuk J, Pye S. Diurnal rhythm in endogenous glucose production is a major contributor to fasting hyperglycaemia in type 2 diabetes. Suprachiasmatic deficit or limit cycle behaviour? Diabetologia 2006; 49:1619-28. https://doi.org/10.1007/s0012 5-006-0273-9. 
24. Lin HV, Accili D. Hormonal regulation of hepatic glucose production in health and disease. Cell Metab 2011; 14:9-19. https://doi.org/10.1016/j.cmet.2011.06.003.

25. Van Cauter E, Shapiro ET, Tillil H, Polonsky KS. Circadian modulation of glucose and insulin responses to meals: Relationship to cortisol rhythm. Am J Physiol 1992; 262:E467-75. https://doi.org/10.1152/ajpendo.1992.262.4.E467.

26. DeFronzo RA. Pathogenesis of type 2 diabetes mellitus. Med Clin North Am 2004; 88:787-835, ix. https://doi.org/10.1016/j. mcna.2004.04.013.

27. Færch K, Vistisen D, Pacini G, Torekov SS, Johansen NB, Witte DR, et al. Insulin resistance is accompanied by increased fasting glucagon and delayed glucagon suppression in individuals with normal and impaired glucose regulation. Diabetes 2016; 65:3473-81. https://doi.org/10.2337/db16-0240.
28. Monnier L, Colette C, Dejager S, Owens D. Magnitude of the dawn phenomenon and its impact on the overall glucose exposure in type 2 diabetes: Is this of concern? Diabetes Care. 2013; 36:4057-62. https://doi.org/10.2337/dc12-2127.

29. Monnier L, Colette C, Dunseath GJ, Owens DR. The loss of postprandial glycemic control precedes stepwise deterioration of fasting with worsening diabetes. Diabetes Care 2007; 30:263-9. https://doi.org/10.2337/dc06-1612.

30. Inzucchi SE, Bergenstal RM, Buse JB, Diamant M, Ferrannini E, Nauck $M$, et al. Management of hyperglycemia in type 2 diabetes: A patient-centered approach: Position statement of the American Diabetes Association (ADA) and the European Association for the Study of Diabetes (EASD). Diabetes Care 2012; 35:1364-79. https://doi.org/10.2337/dc12-0413. 